\section{Stem cell treatments for} neurodegenerative diseases: challenges from a science, business
and healthcare perspective

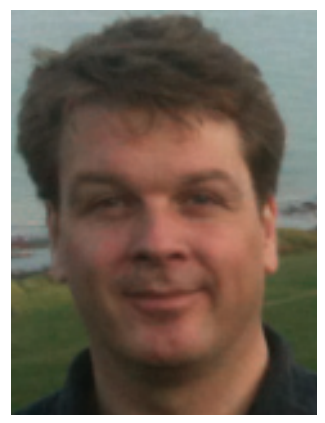

\author{
“ If the implementation costs for stem cell-based \\ treatments for neurodegenerative diseases \\ cannot be reduced ... this emerging group of \\ therapies may be affordable only to a smaller \\ group of wealthy patients."
}

\section{Disease Management}

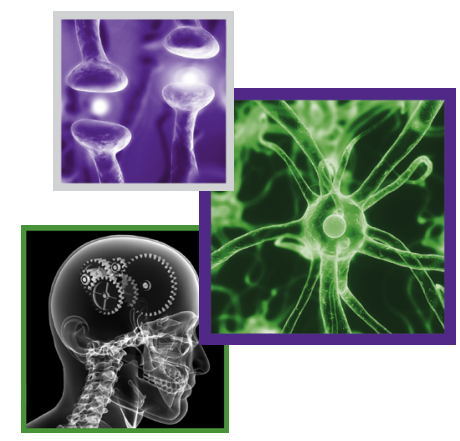

\section{Achim Rosemann*}

Profits in medicine are typically justified by the notion of a 'social contract' between science and society: pharmaceutical and biotech companies are permitted to charge high fees, because revenues are reinvested into research and these investments result in new drugs and the improved health of citizens. A central premise of this model is, however, that the development of novel medicines is financially sustainable: new drugs must be sold in high quantities and be subsidized by welfare state arrangements, so that development costs can be transformed into surplus and future discovery. In the emerging field of stem cell medicine, though, it is still uncertain whether these aims can be achieved. In this article I will discuss this situation with a particular emphasis on neurodegenerative disease research. Although the development of marketable stem cell treatments for neurodegenerative and other neurological diseases is now within reach, it is an open question to what extent these emerging therapeutic strategies can be translated into affordable and widely accessible routine applications. The successful marketing of these treatments and, in particular, the facilitation of widespread and equitable access by patients are affected by various challenges. In this article, three central factors that hinder the translation of the therapeutic potential of stem cells into routine, reimbursable healthcare practice will be discussed: unresolved scientific challenges, the risk of unsustainable development costs and the problem of integrating expensive stem cell treatments into national healthcare portfolios.

\section{Scientific challenges}

Cell therapy applications have now reached advanced clinical trial phases for stroke, Parkinson's diseases, amyotrophic lateral sclerosis and other neurodegenerative disorders, with potential marketing approvals in the foreseeable future [1]. Advancements in research with induced pluripotent stem cells (iPS), moreover, hold promise for the development of additional treatment options [2]. However, despite a growing body of evidence that stem cell-based strategies for patients with neurodegenerative diseases can be effective, there are many obstacles

*Centre for Bionetworking, School of Global Studies, University of Sussex, Arts C 206, Brighton, BN1 9SJ, UK; Tel.: +44753832 9625; ar253@sussex.ac.uk

\section{KEYWORDS}

- access to medicines $\bullet$ affordability

- healthcare decisions $\bullet$ IPS cells

- neurodegenerative diseases $\bullet$ stem cell medicine

\footnotetext{
"For clinical investigators and small-to-mid-size companies that invest in the development of treatments for neurodegenerative diseases, the high costs of drug development are difficult to cover."
} 
“Healthcare systems worldwide are under pressure." to be overcome before these treatments can be approved as safe and successful routine applications. These challenges range from the reliable characterization of cell types, to the development of scalable methods for accurate cell production, to difficulties regarding cell purification, directed differentiation and the control of cell development following transplantation [3]. All of these issues are linked to potential health risks for human research participants and patients, such as tumorigenicity and functional interference due to undesired cell migration and cell activity [4]. Another problem concerns immunological incompatibility between transplanted cell derivatives and potential recipients, which is particularly salient in the case of human embryonic stem cell treatments [5]. In response to this problem, many researchers focus now on autografts of cells derived from iPS cells, which allow to mitigate the problem of allogeneic immune rejection to some extent. The need to address these issues and to produce stem cell products in a scalable and GMP-compliant way that is safe for patients requires large amounts of finance that further increases development and future application costs.

\section{The risk of unsustainable development costs}

For clinical investigators and small-to-mid-size companies that invest in the development of treatments for neurodegenerative diseases, the high costs of drug development are difficult to cover. Geron Corporation, for example, which developed the world's first human embryonic stem cell (hESC) product that entered clinical trials, had to invest about US $\$ 200,000,000$ in its hESC program, before US FDA approval for a Phase I trial could be obtained. Unfortunately, the trial had to be halted after only five patients, for financial and strategic reasons [6]. It is important to note, though, that - because Geron's groundbreaking work took place in an early phase of hESC research - the costs were much higher than for the development of subsequent hESC products [7]. The reason: drug development costs decrease as a new technology advances, and as regulatory frameworks are getting more mature. Nevertheless, in high-income countries the obligatory conduct of Phase I to Phase III trials, and subsequent product release costs do often run up to hundreds of millions of US dollars [8]. The high expenses of developing stem cell therapies are reflected in the costs of treatment delivery. It is expected that the fees for stem cell-based treatments for neurodegenerative diseases will be between US $\$ 30,000$ and 100,000 [9].

For individualized and technologically more complex iPS cell treatments estimates lie around US $\$ 200,000$ or more [10]. These high costs will clearly decrease the range of potential users. More sophisticated cell products that involve iPS cells or human embryonic stem cells, are especially likely to remain unavailable to large numbers of patients. In the light of this situation, the risk of financial unsustainability is high. It remains to be seen whether development costs can be amortized, and sustainable profits can be generated.

\section{Unaffordability to national healthcare systems}

Healthcare systems worldwide are under pressure. Highly finite financial resources and demographic transformations, in particular the shift toward ageing societies, have resulted in cuts in healthcare budgets and cost-containment measures [11]. These changes, together with the availability of new but costly medicines, devices and diagnostics tools, require tough decisions about which medical products and services can be integrated into national healthcare portfolios. These decisions are based on scientific, social and economic value judgments that aim to maximize equitable access to the most efficient and costeffective treatments. This means that, often, life-saving but too expensive medicines are not covered by national healthcare systems, especially if the money can yield greater benefits in other ways [12]. It is an open question to what extent stem cell treatments will pass the costeffectiveness thresholds that are set by healthcare administrators in different countries. Due to the high application costs, stem cell therapies may be beyond the financial capacity of national healthcare systems. This applies to both economically developed and less developed countries, but the barriers in terms of access and affordability will be more profound in low-to-middle-income countries [9]. As recently pointed out by the stem cell biologists Viviane Tabar and Lorenz Studer, given the high costs that are associated with iPS and other pluripotent cell technology, the integration of these treatments into routine, reimbursable medical practice is highly unlikely [3]. In Japan, though, various measures have been taken in the last 2 years to reduce the production costs of iPS cell therapies. A fast track approval system for the commercialization of stem cell treatments was approved in 2013 [13], and the inventor of iPS 
cells, Shinya Yamanaka, has initiated the creation of a cache of iPS cells that allows for more rapid and less costly forms of clinical application than derivation of IPS cells from individual patients [14]. Whether these measures will succeed in reducing the clinical costs of iPS and other technologically complex cell technologies, and allow for the passing of the cost-effectiveness thresholds of public healthcare services remains to be seen.

\section{Conclusion}

If the implementation costs for stem cell-based treatments for neurodegenerative diseases cannot be reduced, and the cost-effectiveness criteria of public healthcare services cannot be met, this emerging group of therapies may be affordable only to a smaller group of wealthy patients. This development runs counter to the principles that have guided the relationship between medicine and society in most high-income countries during the last decades. It provokes fundamental questions about distributive justice, and the level of inequality that will be acceptable to national healthcare services. Debates on the reimbursement of stem cell treatments are reminiscent to discussions on the costs of drugs for orphan diseases. Similar to many orphan drugs, several stem cell-based therapies will probably not pass the cost-benefit evaluation of national healthcare systems, and the advantages for overall population health are therefore likely to be limited [15]. For some disease indications, however, the high expected expenses of stem cell treatments are likely to be outweighed by the enormous societal cost of these diseases. This may apply in particular to therapies for careintensive and chronic neurodegenerative disorders with a high prevalence, such as Alzheimer's, stroke and Parkinson's diseases. At this moment, though, approved treatments for these conditions still do not exist. Healthcare systems and funding agencies worldwide will have to confront these questions, and reappraise whether investments in the development of pluripotent stem cell treatments offer really the best option and value for money that public and private health services can offer to patients.

\section{Acknowledgements}

The author thanks M. Sleboom-Faulkner and colleagues at the University of Sussex's Centre for Bionetworking. The author would like to thank the two anonymous reviewers for their useful comments.

\section{Financial \& competing interests disclosure}

This article has benefited from a research grant of the UK Economic and Social Research Council: grant RES-06223-2990; and from a research grant of the European Research Council: grant ERC-2011-StG_20101124. The author has no other relevant affiliations or financial involvement with any organization or entity with a financial interest in or financial conflict with the subject matter or materials discussed in the manuscript apart from those disclosed.

No writing assistance was utilized in the production of this manuscript.

\section{References}

1 Buzhor E, Leshansky L, Blumenthal J et al. Cell-based therapy approaches: the hope for incurable diseases. Regen. Med. 9(5), 649-672 (2014).

2 Gao A, Peng Y, Deng Y, Qing H. Potential therapeutic applications of differentiated induced pluripotent stem cells (iPSCs) in the treatment of neurodegenerative diseases. Neuroscience 228, 47-59 (2013).

3 Tabar V, Studer L. Pluripotent stem cells in regenerative medicine: challenges and recent progress. Nat. Rev. Gen. 15, 82-92 (2014).

4 Lee AS, Tang C, Rao SM, Weissman IL, Wu JC. Tumorigenicity as a clinical hurdle for pluripotent stem cell therapies. Nat. Med. 19, 998-1004 (2013).

5 Lin G, Qi OY, Qian X, Lu G. Construction of human embryonic stem cell banks: prospects for tissue matching. In: The
Immunological Barriers to Regenerative Medicine.Fairchild P (Ed.). Springer, NY, USA, 111-128 (2013).

6 Brennan P. Geron Corp. shuts down world's first stem cell trial. OC Science (2011). http://sciencedude.ocregister.com/2011/11/16

7 Keirstead H. Translation of stem cell therapies. Spinal Cord Injury - what are the barriers to cure. Bedford Center Spinal Cord Workshop (2012). www.spinalcordworkshop.org/portfolio-type/

8 Rawlins M. Pharmaceutical companies, government and society. Public

Lecture. Oxford, UK Green Templeton College (2009).

www.gtc.ox.ac.uk/academic/lectures

9 Novel neurotechnologies: intervening in the brain Nuffield Council on Bioethics, London, UK (2013).

http://nuffieldbioethics.org/wp-content/
10 Knoepfler P. Yamanaka on making iPS cells from each patient: 'in reality, we cannot do that'. www.ipscell.com/2012/11/yamanaka-on

11 Kaplan RS, Porter ME. How to solve the cost crisis in health care. Harv. Bus. Rev. 89, 46-52 (2011).

12 Appleby J, Devlin N, Parkin D. NICE's cost effectiveness threshold. BMJ 335, 358-359 (2007).

13 Cyranoski D. Japan to offer fast-track approval path for stem cell therapies. Nat. Med. 19, 510-510 (2013).

14 Cyranoski D. Stem-cell pioneer banks on future therapies. Nature 488, 139 (2012).

15 Simoens S, Picavet E, Dooms M, Cassiman D, Morel T. Cost-effectiveness assessment of orphan drugs. Appl. Health Econ. Health Policy 11(1), 1-3 (2013). 
EDITORIAL Rosemann 